This is the post-print version of the paper that was published in Waste Management.

Reference: McLeod FN and Cherrett TJ (2008). Quantifying the transport impacts of domestic waste collection strategies. Waste Management, 28, 2271-2278.

\title{
QUANTIFYING THE TRANSPORT IMPACTS OF \\ DOMESTIC WASTE COLLECTION STRATEGIES
}

Fraser McLeod ${ }^{*}$ and Tom Cherrett

Transportation Research Group, School of Civil Engineering and the Environment, University of Southampton, UK

*F.N.McLeod@soton.ac.uk, Tel: 0238059 3316, Fax: 02380593152 


\section{Abstract}

This paper models the effects of three different options for domestic waste collection using data from three Hampshire authorities: (i) joint working between neighbouring waste collection authorities; (ii) basing vehicles at waste disposal sites; (iii) alternate weekly collection of residual waste and dry recyclables. A vehicle mileage saving of $3 \%$ was modelled for joint working, where existing vehicle allocations to depots were maintained, which increased to $5.9 \%$ when vehicles were re-allocated to depots optimally. Vehicle mileage was reduced by $13.5 \%$ when the collection rounds were based out of the two waste disposal sites rather than out of the existing depots, suggesting that the former could be the most effective place to keep vehicles providing that travel arrangements for the crews could be made. Alternate weekly collection was modelled to reduce vehicle mileage by around $8 \%$ and time taken by $14 \%$, when compared with a typical scenario of weekly collection of residual and fortnightly collection of recyclable waste. These results were based on an assumption that $20 \%$ of the residual waste would be directly diverted into the dry recyclables waste stream.

Keywords: waste; transport logistics; alternate weekly collection 


\section{Introduction}

Household waste collections are expensive to operate and designing efficient collection strategies is vital not only to reduce operating costs and vehicle emissions, but to maximise the amount of recyclate generated, whilst minimizing any traffic congestion associated with refuse collection vehicle $(R C V)$ operations. Concentrating on local authority domestic collection operations, this paper considers the general cost benefits that may accrue from adopting three different waste collection strategies:

1. Allowing joint working between neighbouring waste collection authorities (WCAs)

2. Using waste disposal sites as vehicle depots for RCVs

3. Switching to alternate weekly collection (AWC) of dry recyclables and residual waste.

\subsection{Joint working}

The phrase 'joint working' is used here to mean neighbouring WCAs sharing their resources (vehicles, crew, depots) and sharing the collections to be made, in effect becoming a single 'super-authority'. This means that rounds can be redesigned, ignoring any existing internal boundaries between the separate authorities. Although some WCAs in the UK already undertake some form of joint working or are interested in doing so (Innovation Forum, 2004), there are few published findings of the benefits. A study of kerbside green waste collection in Hampshire, UK, suggested that the operating costs for one WCA would reduce by $47 \%$ through joint working with two of its neighbours (Jacobs Babtie, 2005), whilst a study quantifying the potential benefits of basing RCVs out of neighbouring 
authority depots in Gloucestershire, UK, suggested that a $22 \%$ reduction in vehicle mileage could be achieved (ENTEC, 2005). This paper provides a useful contribution to knowledge about the potential transport impacts of joint working in waste collection.

\subsection{Using disposal sites as vehicle depots}

The idea considered here is to locate RCV depots at, or close to, waste disposal sites. This idea is a natural one to consider as, in the UK, it is normally required (contractually rather than legally) that RCVs be emptied of all waste before returning to the depot at the end of the working day. Traditional depot location theory is based on finding the centre of the population being served by the vehicles (Hayford, 1902); however, it seems likely that in order to reduce 'deadhead' mileage (driving empty), depots should be situated closer to the waste disposal sites used rather than to the population areas being served. It was assumed in this research that new, optimal depot locations were being sought, while the waste disposal sites were assumed to be in their existing locations.

The combined depot location and vehicle routing problem is notoriously difficult to solve. Typically, the problem is divided in two, solving the depot location problem and vehicle routing problems separately and iterating between them $\mathrm{Wu}$ et al., 2002). Laporte et al. (1989) also considered this problem for a set of customers having random supplies, while Lim and Wang (2005) considered the problem of multiple depots with a fixed distribution of vehicles to the depots; Mina et al. (1998) provided a synthesis of combined location-routing methods. While combined depot location and vehicle routing problems have been studied widely, the requirement 
for the RCV to visit a waste disposal site as the last task of the day, significantly changes the nature of the problem. This aspect of the problem has been little researched, as the requirement to empty the $\mathrm{RCV}$ of waste before returning to the depot is not necessarily standard practice in other countries. This paper does not attempt to solve the problem theoretically but, instead, uses a case study example to evaluate the intuitive 'solution' of basing RCVs at the waste disposal sites, rather than at the existing vehicle depots.

\subsection{Alternate Weekly Collection}

Alternate weekly collection (AWC) refers to a two-week collection cycle where different waste types are collected from each household on alternate weeks. Typically, dry recyclables (paper, cardboard, plastic bottles etc.) will be collected one week and residual waste the following week. This scheme has become popular in the UK in recent years with over 180 local authorities (46\%) having changed over to AWC by April 2007 (WRAP, 2007). The most commonly raised objection to AWC is that the reduction in collection frequency may lead to health issues associated with food waste being left in bins for nearly two weeks, particularly in densely populated areas; recent research in the UK has recommended that food waste be collected separately and weekly (WRAP, 2007). However, this is not currently done and this paper focuses on existing practice. One of the main benefits of AWC is that the reduced collection frequency of residual waste encourages householders to recycle and increases recycling rates: of the top 20 highest performing UK local authorities in 2005/06, in terms of recycling rates, 19 were operating an AWC scheme (WRAP, 2007). Authorities currently operating weekly residual waste collections with fortnightly co-mingled 
recyclable collections could make immediate savings in terms of fleet size from going to the AWC system. The level of transport benefit from AWC is not well reported and this paper provides a useful contribution in this area.

\section{Modelling domestic waste collections}

Waste collection vehicle routing can be formulated either as an arc routing problem (having to traverse a set of roads) or as a node routing problem (having to visit a number of points). Arc routing is perhaps the more natural formulation as waste collections are normally made from most of the roads that comprise the network (Dror, 2000). It can also be modelled as a node routing problem where specific weights of waste are identified as collections at a number of specified points on the round (Nuortio et al., 2006). The shortest path route between the collection points is then determined, ideally traversing roads once whilst minimising the 'deadhead' mileage associated with crossing non-demand areas.

The problem of routing and scheduling waste collection vehicles falls into the class of capacitated vehicle routing problems (CVRP), where the routing is constrained by vehicle capacity, working hours, disposal site opening hours and other factors. Although exact algorithms for solving CVRP have been devised they cannot be used for large practical problems as they require too much computation time (Baldacci and Maniezzo, 2006). Consequently, a multitude of 'non-exact', heuristic solution methods have been proposed in the literature (Toth and Vigo, 2001). 'Tabu search' methods (Glover and Laguna, 1997) have been applied to waste collection with varying levels of success (Archetti et al., 2006; Chang and Wei, 2000a; De Rosa et al., 2002). Genetic algorithms (Mitchell, 1996) have been 
applied to waste collection problems and found to be more robust compared to traditional search methods, less prone to getting stuck at local optima and quicker to run (Chang and Wei, 2000b; Viotti et al., 2003). Fuzzy logic methods (Mendel, 2000) have also been used and are more able to handle problems with imprecise and incomplete data, such as uncertain waste volume. Such approaches have been used to determine optimal bring-site locations (Chang and Wei, 2000b) as part of a collection schedule. Eisenstein and lyer (1997) modelled household waste collection in Chicago as a Markov process, where the probability of the next event depends on the probability of events that have occurred recently. They devised a dynamic scheduling algorithm which was adaptive to the volume of waste being collected and improved vehicle capacity utilisation.

A technique commonly used in waste collection practice is to sub-divide the collection area into a number of smaller areas to be treated separately. This subdivision technique is known as 'districting' and has also been used to simplify modelling (Hanafi et al., 1999, Chang et al., 1997).

Since the main objective of this study was to evaluate the potential effectiveness of different waste collection strategies on the ground, rather than to contribute to vehicle routing theory, a commercially-available node routing software package, LogiX (DPS International, 2007), was used. The features of this model which made it particularly suitable were that it used street-level mapping (which allowed detailed routes to be calculated), and allowed certain characteristics to be replicated, e.g. multiple depot locations (allowing modelling of joint working between neighbouring authorities, each with their own existing vehicle depot), 
different vehicle types (allowing different vehicle capacities to be specified for residual waste and recyclable waste), different crew working hours and waste disposal site opening hours. The overall principles of the software are to complete the maximum amount of work within the minimum amount of time, based on the available road network, whilst obeying the restrictions specified by the user. As LogiX is a commercial software package, the detailed algorithms used within it are not known to the authors; however the algorithms employ clustering, insertion, swapping and resequencing methods.

\section{Data collection and methodology}

\subsection{Case study area}

The case study area (Figure 1) comprised 130,000 households across three neighbouring WCA districts in Hampshire, UK (Basingstoke and Deane, Hart and Rushmoor). One-fifth of all the collection rounds were explicitly modelled, equating to 25 'sub-rounds', where a sub-round was defined as the work done by one RCV and crew on one day. The sub-rounds closest to the inter-district boundaries were chosen as these were the most likely to benefit from joint working between the authorities. Each WCA was responsible for its own domestic waste collection and operated out of its own, or its contractor's depot, taking waste to the two main waste disposal sites (Chineham, an energy recovery facility near Basingstoke, and Farnborough, a transfer station). Onward movement of waste from the transfer station was not considered in the study. 


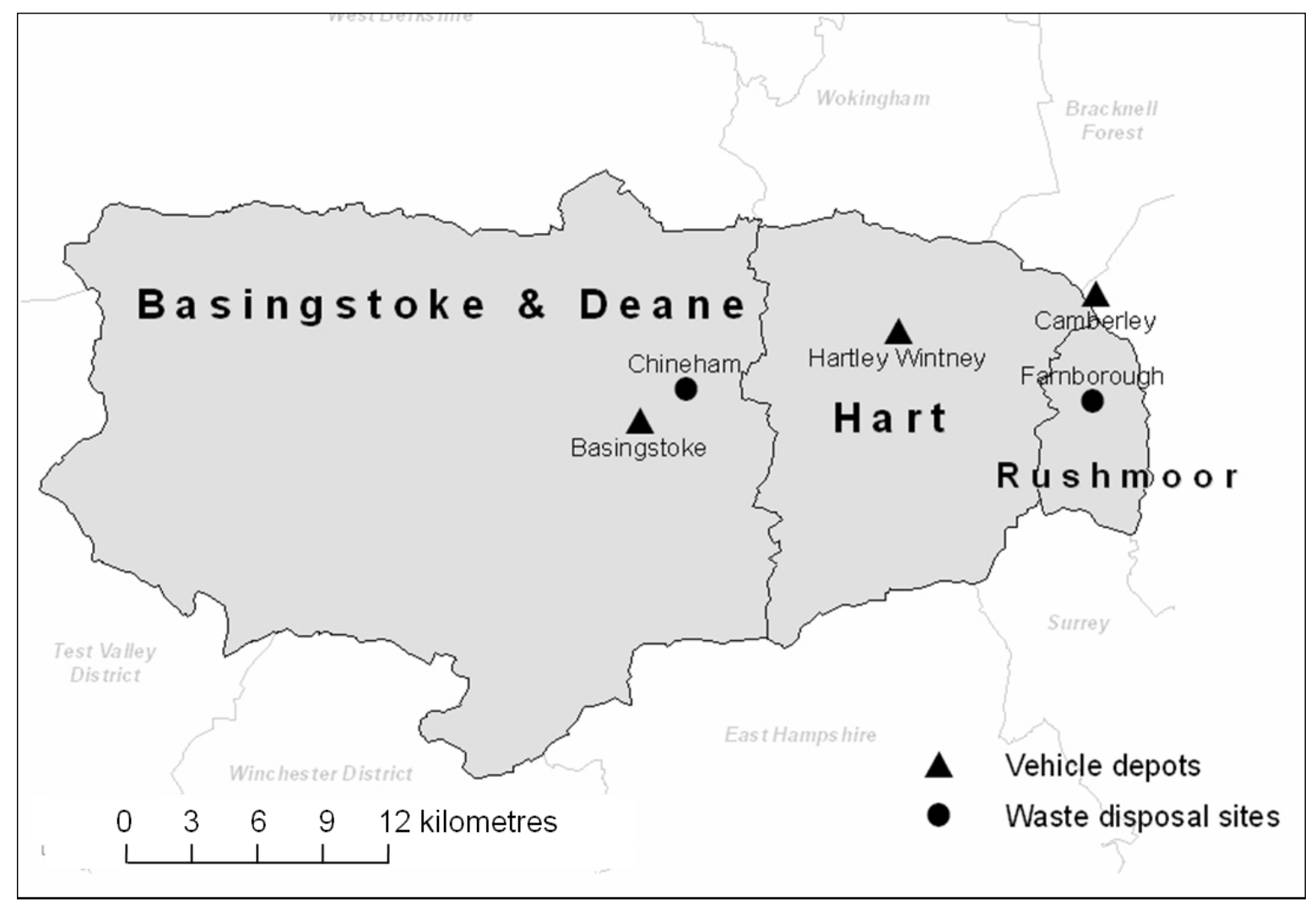

Figure 1 - Case study area (North Hampshire)

\subsection{Data collection and preparation}

Modelling waste collection rounds accurately requires a large amount of detailed data. The data supplied by the three Hampshire WCAs, and used to calibrate the routing model, included round specific routing information, the weight of waste collected by round $(\mathrm{kg})$, the time taken (including disposal time) and the individual vehicle specifications. One interesting point made by some WCA managers was that routes taken around the specified collection areas were left to the discretion of the driver and could vary from week to week. This meant that in some cases, there were no fixed 'existing routes', and the routes supplied were considered as 'typical'. It is also noted that waste volumes may vary from week to week so the problem faced is stochastic in nature. The general approach for stochastic vehicle 
routing problems is to generate a least-cost, a priori, expected solution (Nuortio et al., 2006). This approach was adopted here, modelling average typical loads, as it was outside the scope of this study to consider how rounds would have to be adjusted in practice to handle seasonal variation. The reader is referred to Dror et al. (1989) for a discussion of stochastic vehicle routing problems. The waste data were aggregated to postcode level, with the number of houses in each postcode area and the average round weight being used to calculate the weight of waste to be collected from each postcode. This level of aggregation was considered to be detailed enough to give a sufficiently accurate representation of the collections and coarse enough to allow a manageable round optimisation task.

\subsection{Analysis method}

The model (LogiX) allowed both existing and optimised routes and schedules to be calculated. The existing collection rounds were as specified by the WCAs after translation into ordered lists of postcodes. A detailed validation of the modelled existing collection rounds, in terms of routes taken, was not possible due to the daily fluctuations in collection order; however, the modelled round times were scrutinised by the waste collection managers at each authority and the model parameters (e.g. collection time per kg waste) adjusted as necessary to produce accurate round times.

Before considering the different waste collection strategies under investigation, the improvements that could be made by simply optimising the existing collections were quantified. This was undertaken as a two-stage process to assess the incremental benefits that may be achieved by: 
(i) optimising the routes taken on each of the existing rounds

(ii) optimising the round structures and the routes taken on the newly designed rounds.

The different waste collection strategies and scenarios considered here were compared to base cases where the existing routes and round structures were optimised, meaning that any reported benefits were over and above those available from optimising existing routes and round structures. This approach ensured that strategies were compared fairly and that the results did not reflect how well the existing routes and round structures had been set up by the WCAs.

\section{Optimising the existing collection method}

\subsection{Route optimisation}

The routes taken on each of the existing sub-rounds were optimised and compared with the modelled existing routes. The typical modelled saving was between 10-15 minutes but in one extreme case, a saving of more than one hour was modelled. This was due to the two tipping points (the points in the round where the RCV has become full and must visit the waste disposal site) on the existing route being poorly positioned, involving long journeys to the waste disposal site, a problem which was resolved by the modelled optimal route.

\subsection{Round structure optimisation}

The round structures (which collections are allocated to which rounds) within each of the three authority areas were optimised separately. The results from this were 
compared with the modelled existing round structures (Figure 2). The three authority areas in Figure 2 have been labelled A, B and C (in no particular order) to disguise the identity of each, and avoid any suggestion of inefficiency for a particular WCA. The results suggested that the existing round structures ranged from being near optimal, for authority $A$, to a distance and time saving of nearly $14 \%$ and $6 \%$ respectively for authority $C$. These equate to an annual distance saving of $6,120 \mathrm{~km}$ for the selected sub-rounds, or $22,000 \mathrm{~km}$ for the whole of the WCA, if similar benefits were realised on their remaining sub-rounds. The level of savings that may be achieved from updating and optimising existing routes and schedules naturally depends on how well the existing collection rounds have been designed and how frequently they are updated to allow for road network alterations or new housing developments.

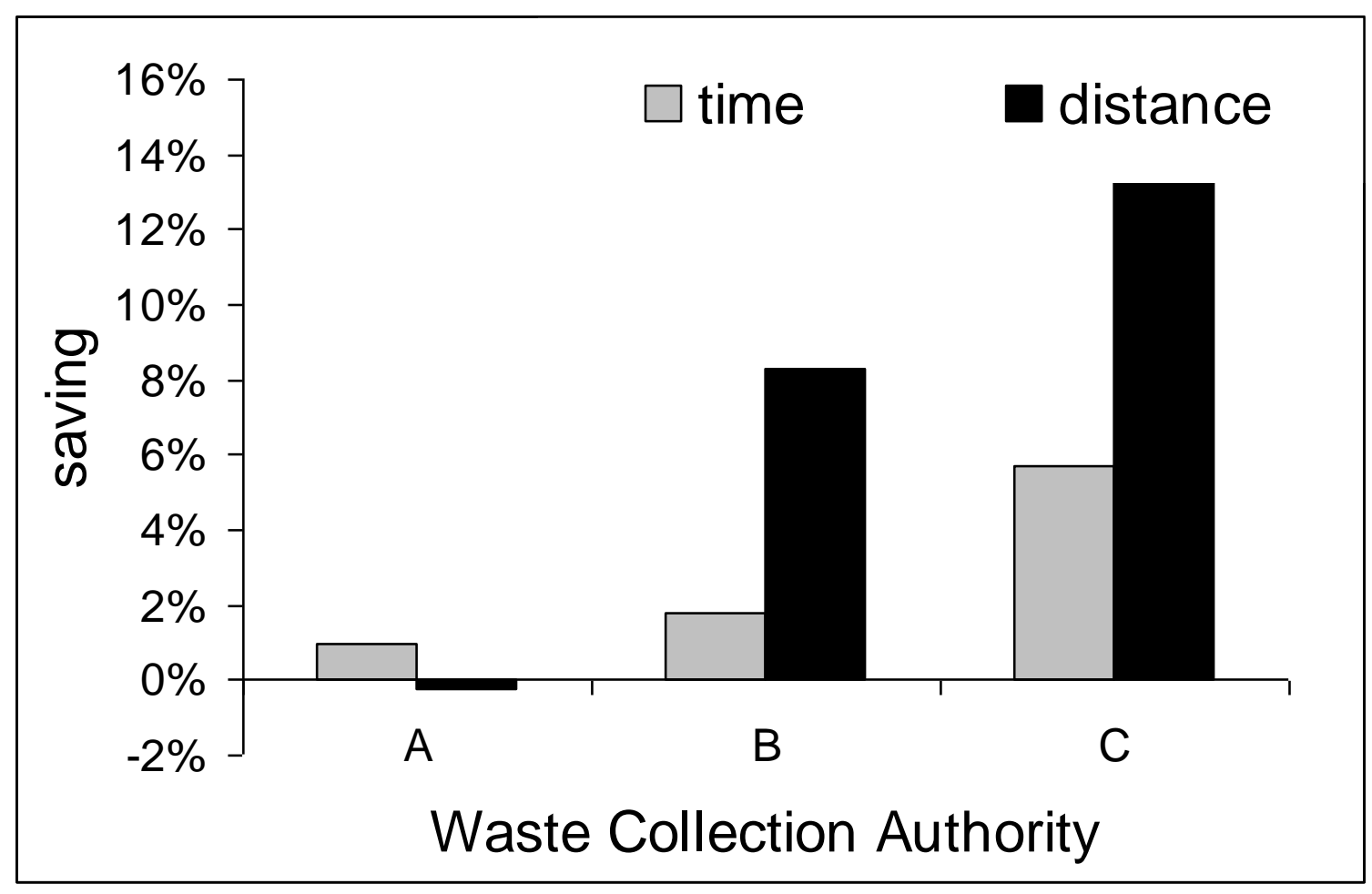

Figure 2 - Percentage savings from optimising round structures 
The optimised collection rounds were presented to the collection managers for comment and to determine how the round constraints might impact on the suggested changes in each case. Of significant interest were the potential benefits of re-scheduling the tipping points in the round to reduce 'deadhead' mileage. It is recognised that for a practical implementation on-street it would be necessary for crews to check the routes in detail and to adjust them as necessary to take the various constraints into account (e.g. main roads where collections have to be made before the morning peak). In addition, for an on-street implementation, modelling would have to be undertaken for the whole case study area, not just for the $20 \%$ of collection rounds selected for the study.

\section{Joint working between neighbouring WCAs}

\subsection{Maintaining existing depot allocation of sub-rounds}

In the first scenario considered, the residual waste sub-rounds were allocated among the three depots according to the existing situation - seven sub-rounds based at Basingstoke and Deane's depot, nine at Hart's depot and nine at Rushmoor's depot - but the model was free to allocate collections across authority boundary lines. This resulted in a time saving of $0.8 \%$ (approximately $3 \frac{1}{2}$ minutes per sub-round) and a vehicle mileage saving of $3 \%$ (approximately $1.7 \mathrm{~km}$ per subround). The annual distance savings were estimated to be approximately $2,200 \mathrm{~km}$, based on the selected sub-rounds only. These savings could not be readily extrapolated to the whole case study area because the impact of joint working on other rounds, further away from the inter-district boundaries, would be less pronounced. The new rounds demonstrated high levels of joint working between 
the authorities, particularly between Hart and Rushmoor, where approximately one third of the work done was outside their own district (Table 1).

Table 1 - Proportion of work undertaken in each district

\begin{tabular}{|c|c|c|c|c|}
\hline \multirow{2}{*}{$\begin{array}{l}\text { Vehicle } \\
\text { Depot }\end{array}$} & \multirow{2}{*}{$\begin{array}{l}\text { Number of } \\
\text { sub-rounds }\end{array}$} & \multicolumn{3}{|c|}{$\begin{array}{l}\text { Percentage of work } \\
\text { undertaken in area }\end{array}$} \\
\hline & & $\begin{array}{l}\text { Basingstoke } \\
\text { and Deane }\end{array}$ & Hart & Rushmoor \\
\hline Basingstoke and Deane & 7 & $88 \%$ & $12 \%$ & $0 \%$ \\
\hline Hart & 9 & $6 \%$ & $67 \%$ & $27 \%$ \\
\hline Rushmoor & 9 & $0 \%$ & $32 \%$ & $68 \%$ \\
\hline
\end{tabular}

Table 1 - Proportion of work undertaken in each district

\subsection{Optimal depot allocation of sub-rounds}

In the second scenario considered, the sub-rounds were allowed to be based out of any of the three available depots. The number of sub-rounds reduced by one (from 25 to 24) with 11 based at the Basingstoke and Deane depot, 11 at Rushmoor and only two at the Hart depot. This result reflected the fact that the selected sub-rounds, chosen to be close to the inter-district boundaries, were closest to the Basingstoke and Deane and Rushmoor depots. Overall time taken was reduced by $1.4 \%$ (approximately 6 minutes per sub-round) with a vehicle mileage saving of $5.9 \%$ (approximately $3.3 \mathrm{~km}$ per sub-round). The annual distance savings for the selected rounds were estimated to be $4,300 \mathrm{~km}$ but these results could not be readily extrapolated to the whole case study area. This result demonstrates that for these selected rounds, it would be beneficial to reallocate vehicles and crews between the depots. In practice, such decisions would have to 
consider the wider vehicle/crew requirements across all the collection rounds, not only on selected rounds.

\section{Using waste disposal sites as vehicle depots}

\subsection{Modelling results}

The disposal sites were modelled as having depot facilities and the sub-rounds optimally allocated to them (nine operating out of Chineham and sixteen operating out of Farnborough). Under this scenario, and allowing cross-boundary collections, the overall time taken was reduced by $3 \%$ (131/2 minutes per sub-round) and vehicle mileage by $13.5 \%$ (7.7km per sub-round) with annual distance savings for the selected rounds estimated to be $10,000 \mathrm{~km}$. When the model was offered a choice of five depot sites to use (the three existing vehicle depots and the two waste disposal sites), the latter were preferred for use on all of the sub-rounds over the existing depots, suggesting the optimality of the waste disposal sites as depots in terms of reducing RCV mileage. Using the waste disposal sites as depots was also tested on some other sub-rounds, further away from the waste disposal sites to assess the robustness of the method and similar conclusions were drawn from the results.

\subsection{Crew travel requirements}

The RCV mileage is not the only travel associated with waste collection. The vehicle crew have to travel from their homes to the depot each day and this should also be considered if the wider transport costs and environmental implications are of interest. If a WCA was considering moving its depot closer to a waste disposal site, or siting vehicles at a disposal facility, then this may have an overall negative 
environmental impact if the crew have to travel further to their work. This problem would be alleviated if some form of shared transport (e.g. a minibus) was available. A simplistic analysis of the impacts is now presented:

Let:

$\mathrm{N}_{\mathrm{E}}=$ number of vehicle trips associated with the drivers and crew travelling to and from the existing depot

$\mathrm{M}_{\mathrm{E}}=$ average distance of these trips

$\mathrm{N}_{\mathrm{W}}=$ number of vehicle trips associated with drivers and crew travelling to and from the new depot location (e.g. at the waste disposal site)

$\mathrm{M}_{\mathrm{W}}=$ average distance of these trips

Then if $\left(N_{E} \times M_{E}\right)-\left(N_{W} \times M_{W}\right)$ is greater than the estimated RCV mileage saving then there would be an overall negative effect.

\section{Alternate weekly collection}

\subsection{Modelling assumptions}

In this scenario, alternate weekly collection (AWC) of residual and recyclable waste was compared to a weekly collection of residual and fortnightly collection of recyclable waste, a commonly used collection arrangement in Hampshire. A detailed analysis was undertaken using 10 of Rushmoor district's sub-rounds. Typical practice when implementing AWC is to divide the collection area into two parts of roughly equal size and to collect residual waste from one area and recyclable waste from the other in one week and vice versa the next week. This is done to ensure an even workload between weeks. The two sub-areas (A and B) 
both comprised five of the existing sub-rounds grouped geographically to reduce the amount of travel required in each sub-area.

It was assumed that by introducing AWC the weight of residual waste would be reduced by $20 \%$ (this figure being the minimum hoped for by the three Hampshire authorities in the case study area who were all planning a move to AWC at the time of this study). It was also assumed that all of this reduction in residual waste would be diverted into the dry recyclables waste stream. From the modelled weights of residual waste and recyclable waste, before and after AWC (Table 2), the recycling rate increased from $20 \%$ to $36 \%$.

Table 2 - Waste to be collected in each area (tonnes per week)

\begin{tabular}{lcccc}
\hline Waste (tonnes per week) & Area A & Area B & $\begin{array}{c}\text { Whole } \\
\text { Area }\end{array}$ & $\begin{array}{c}\text { Percentage } \\
\text { of total }\end{array}$ \\
\hline Residual waste (base case) & 92.9 & 85.9 & 178.8 & $80 \%$ \\
Recyclable waste (base case) & 24.0 & 22.1 & 46.1 & $20 \%$ \\
Residual waste (AWC) & 74.3 & 68.7 & 143.0 & $64 \%$ \\
Recyclable waste (AWC) & 42.6 & 39.3 & 81.9 & $36 \%$ \\
$\begin{array}{l}\text { Total residual waste + } \\
\text { recyclable waste }\end{array}$ & 116.9 & 108.0 & 224.9 & - \\
\hline
\end{tabular}

Table 2 - Waste to be collected in each area (tonnes per week)

In practice, it seems likely that some residual waste would be diverted into other waste streams such as home composting or taken to household waste recycling centres, which would mean that the combined total of residual and recyclable waste would be reduced by AWC. However, it was decided not to attempt to model this complex behaviour as detailed data were not available. 
Two other associated factors were considered to be important to model here:

- Collection time per bin - With the introduction of AWC the average bin weights for both residual and recyclable waste are likely to increase considerably. In the case of residual waste, due to the longer time period between collections, and in the case of recyclable waste, due to diversion of waste from the residual into the recyclable waste stream. Under the modelling assumptions used, residual waste bin weights increased from $11.3 \mathrm{~kg}$ to $18.1 \mathrm{~kg}(60 \%)$ and recyclable waste bin weights from $5.8 \mathrm{~kg}$ to $10.4 \mathrm{~kg}(78 \%)$. Heavier bins are likely to take longer to drag to the RCV and load onto the lifting apparatus for emptying. No data were available to confirm this, so two different assumptions were evaluated:

1. A constant collection time of $12.5 \mathrm{~s} /$ bin for both waste types and for both before-and-after AWC, derived from the overall round times stated by the WCAs. Using this assumption, the modelled sub-round times were $24 \%$ shorter after the introduction of AWC as the number of bins that could be collected had also reduced by $24 \%$ due to the increased bin weights and the RCV capacity constraint.

2. As in point 1 above, with the exception that after the introduction of AWC, the collection time per bin for residual waste increased to $17.5 \mathrm{~s} / \mathrm{bin}$, this increased value being chosen to produce sub-round times similar to the base case, that is 7.5 hours, on average.

- Bin set-out rate - Set-out rates of $100 \%$ for residual and $80 \%$ for recyclable waste were assumed for the AWC case, using figures supplied by one of the 
Hampshire authorities. With the introduction of AWC, it seemed likely that more householders would set their recycling bin out for collection, as they are liable to fill more quickly and householders may not want to risk missing a collection in case they run out of bin capacity. As there were no data available on this aspect, two set-out rates were evaluated: $80 \%$ (existing situation) and 100\% (maximum possible).

\subsection{AWC results}

Four AWC scenarios were modelled by varying the collection time for residual waste and the bin set-out rate as described in section 7.1 (Figure 3). Time taken was reduced by between $14 \%$ and $30 \%$ and the total RCV mileage was reduced by $8 \%$, from $1165 \mathrm{~km}$ to $1068 \mathrm{~km}$, for all four of the AWC scenarios considered. The scenario with a $100 \%$ recycling bin set-out rate and a collection time per bin of $17.5 \mathrm{~s}$ is perhaps the most realistic of those modelled, however this would have be verified in the field. 


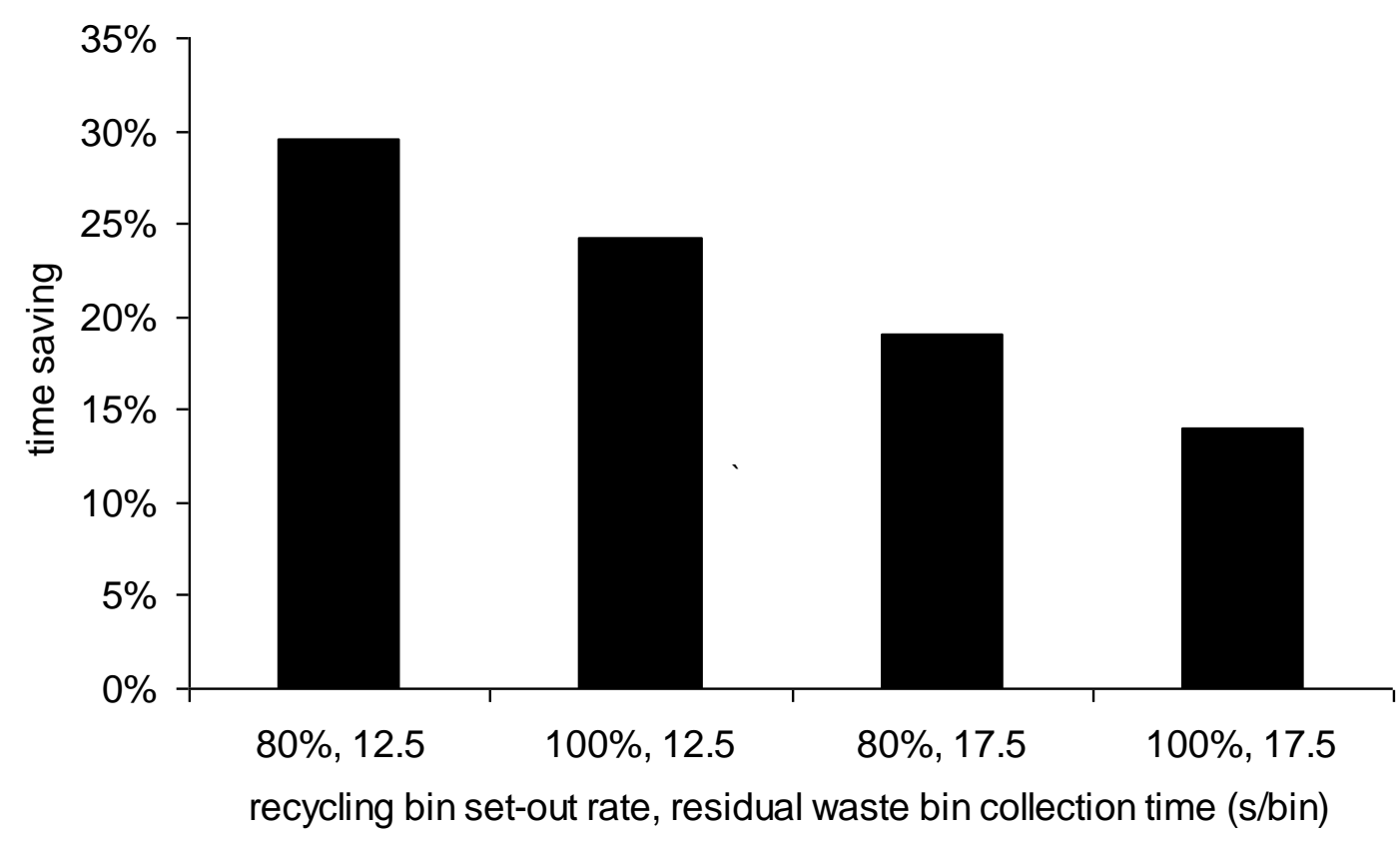

Figure 3 - Range of time savings through converting to alternate weekly collection

\section{Conclusions}

Using domestic collection round data from three Hampshire authorities, this paper describes the vehicle mileage and time savings that may be achieved from adopting various waste collection strategies, namely joint working between neighbouring authorities, alternate weekly collection and locating vehicle depots closer to waste disposal sites. A routing and scheduling package (Logix) was used to model the existing collection rounds and quantify the benefits of various new operating scenarios. The model suggested that significant savings could be achieved from updating the existing vehicle collection rounds with one of the studied authorities reducing their vehicle mileage on the selected collection rounds by $14 \%$ through round restructuring. Optimising the round 'tipping points' (the point at which the vehicle becomes full and has to go to the waste disposal site) was a 
key factor in this reduction as tipping points should be situated as close to the waste disposal site as possible to minimise the 'deadhead' time and distance travelled.

Joint working between neighbouring waste collection authorities is of practical interest to those seeking operational improvements through sharing resources and responsibilities. The modelling results, where existing vehicle allocations to depots were maintained, suggested that vehicle mileage and round time reductions from, joint working may be small ( $3 \%$ mileage and $0.8 \%$ time saving). These savings increased to $5.9 \%$ and $1.4 \%$, respectively, when vehicles were re-allocated to depots optimally. It seems likely that joint working benefits would most pronounced in areas where large numbers of households are located either side of the existing authority boundary and greater benefits could be achieved in metropolitan areas such as London or Birmingham than those found here for north Hampshire. It is also worth noting that joint working may offer other benefits such as the sharing of vehicle maintenance facilities and the provision of 'spare' vehicles in the event of breakdowns (Jacobs Babtie, 2005).

From the point of view of reducing refuse collection vehicle mileage, the best place to set up a vehicle depot would be close to, or at, the waste disposal sites, with reductions in vehicle mileage of $13.5 \%$ being modelled. This reduction equated to an annual saving of around $10,000 \mathrm{~km}$ for the selected collection rounds only, which covered one-fifth of the whole case study area. Depots situated at disposal facilities would depend on space availability and an operator's licence holder being registered at the site related to the vehicles involved. If overall vehicle mileage, 
including staff journeys to and from work, was taken into account, then depot sites may be better placed within, or close to, the urban centres where the majority of staff live.

Alternate weekly collection of residual and recyclable waste was modelled to reduce vehicle mileage by $8 \%$ and time taken by $14 \%$, when compared with a common scenario of weekly residual and fortnightly recyclable collections. These results were based on the assumption that $20 \%$ of the residual waste would be directly diverted into the dry recyclable waste stream. Under this assumption, it was noted that the modelled bin weights increased substantially, with the average residual waste bin weight at the time of emptying increasing from $11.3 \mathrm{~kg}$ to $18.1 \mathrm{~kg}$, a $60 \%$ increase, and the average recyclable waste bin increasing from $5.8 \mathrm{~kg}$ to $10.4 \mathrm{~kg}$, a $78 \%$ increase. It should be noted that heavier bins mean reduced vehicle carrying capacity, in terms of the number of bins that can be emptied on a round, and could also adversely impact on the health and safety of the crews.

\section{Acknowledgements}

The authors would like to acknowledge the support provided by the Project Officer, Roger Worth (Department for Transport) and Steve Read (Executive Officer, Project Integra). The authors would also like to thank the waste collection authority managers of Basingstoke and Deane, Hart and Rushmoor, and the contractors, Cleanaway and Onyx, for the considerable amount of data and useful information they supplied. The views expressed in this paper are those of the authors and may 
not necessarily represent the policy or views of the Department for Transport, Project Integra or the individual waste collection authorities involved in the project. 


\section{References}

Archetti, C., Speranza, M.G. and Hertz, A., 2006. A Tabu Search Algorithm for the Split Delivery Vehicle Routing Problem, Transportation Science, 40, 64 - 73.

Baldacci, R. and Maniezzo, V., 2006. Exact Methods Based on Node-Routing Formulations for Undirected Arc-Routing Problems. Networks, 47(1), 52-60.

Chang, N.B., Chang, Y.H. and Chen, Y.L., 1997. Cost-Effective and Equitable Workload Operation in Solid-Waste Management Systems. Journal of Environmental Engineering. 123(2), 178-190, American Society of Civil Engineers.

Chang, Y.L. and Wei, N.B., 2000a. Comparative study between the heuristic algorithm and the optimization technique for vehicle routing and scheduling in a solid waste collection system. Civil Engineering and Environmental Systems, 19(1), 41-65.

Chang, Y.L. and Wei, N.B., 2000b. Siting recycling drop-off stations in urban areas by genetic algorithm-based fuzzy multiobjective nonlinear integer programming modelling, Fuzzy Sets and Systems, 114, 133-149.

De Rosa, B., Improta, G., Ghiani, G. and Musmanno, R., 2002. The arc routing and scheduling problem with transshipment, Transportation Science, 36(3), 301313. 
DPS International, 2007. Webpage: DPS Logix Suite - http://www.dpslogix.co.uk/ (accessed 28 August 2007)

Dror, M., Laporte, G. and Trudeau, P., 1989. Vehicle routing with stochastic demands: properties and solution frameworks, Transportation Science, 23, 166176.

Dror, M., 2000. Arc routing: theory, solutions and applications. Kluwer Academic Publishing, Boston, Massachusetts, USA.

Eisenstein, D.D. and lyer, A.V., 1997. Garbage Collection in Chicago: A Dynamic Scheduling Model, Management Science, 43(7), 922-933.

ENTEC UK Limited, 2005. Exploring Logistics for Recycling Opportunities, Report to The Recycling Consortium, September 2005.

Glover, F.W. and Laguna,M., 1997. Tabu Search, Kluwer Academic Publishers, Boston, Massachusetts, USA.

Hanafi, S., Freville, A. and Vaca, P., 1999. Municipal solid waste collection: an effective data structure for solving the sectorization problem with local search methods, INFOR, 37(3), 236-254.

Hayford, J., 1902. What is the center of an area, or the center of a population? Journal of the American Statistical Association, 8, 47-58. 
Innovation Forum, 2004. Joint working in two-tier authorities, Report of a symposium held on 8/12/2005. Available at http://www.idea-knowledge.gov.uk/idk /aio/1720279 (accessed 28 August 2007).

Jacobs Babtie, 2005. Project Integra. Maximising Collection Efficiency, DEFRA Waste Implementation Programme Local Authority Support Unit (WIPLASU).

Laporte, G., Louveaux, F. and Mercure, H., 1989. Models and exact solutions for a class of stochastic location-routing problems. European Journal of Operational Research, 39(1), 71-78.

Lim, A. and Wang, F., 2005. Multi-Depot Vehicle Routing Problem: A One-Stage Approach. IEEE Transactions on Automation Science and Engineering, 2(4), 397402.

Mendel, J., 2000. Uncertain Rule-Based Fuzzy Logic Systems: Introduction and New Directions. Prentice-Hall Inc, Upper Saddle River, New Jersey, USA.

Mina, H., Jayaraman, V. and Srivastava, R., 1998. Combined location-routing problems: A synthesis and future research directions. European Journal of Operational Research, 108(1), 1-15.

Mitchell, M., 1996. An introduction to genetic algorithms. MIT Press, Cambridge, Massachusetts, USA. 
Nuortio, T., Kytöjoki, J., Niska, H. and Bräysy, O., 2006. Improved route planning and scheduling of waste collection and transport. Expert Systems with Applications, 30(2), 223-232.

Toth, P. and Vigo, D., 2001. The vehicle routing problem. Society for Industrial and Applied Mathematics, Philadelphia, Pennsylvania, USA.

Viotti, P., Polettini, A., Pomi, R. and Carlo, I., 2003. Genetic algorithms as a promising tool for optimisation of the MSW collection routes. Waste Management Research, 21(4), 292-298.

WRAP, 2007. Alternate weekly collections guidance. Report written by Entec for the Waste and Resources Action Programme (WRAP). Available at: http://www. wrap.org.uk/downloads/AWC_Revised_Final_Report_-_130707.e240cc9d.PDF (accessed 28 August 2007).

Wu, T.H., Low, C. and Bai, J.W., 2002. Heuristic solutions to multi-depot locationrouting problems. Computers and Operations Research, 29(10), 1393-1415. 